\title{
A PRESCRIPTION AUDIT AND ASSESSMENT OF DRUG UTILIZATION PATTERN IN A TERTIARY CARE TEACHING AND REFERRAL HOSPITAL IN UTTAR PRADESH, INDIA
}

\author{
SURABHI ARORA, AFROZ ABIDI*, DILSHAD ALI RIZVI \\ Department of Pharmacology, Era's Lucknow Medical College and Hospital, Lucknow, Uttar Pradesh, India. Email: afrozabidi@gmail.com \\ Received: 19 August 2019, Revised and Accepted: 31 October 2019
}

\begin{abstract}
Objective: The objective of our study is to assess the prescription and drug utilization pattern in a tertiary care teaching and referral hospital in Uttar Pradesh, to investigate the rational use of drugs.

Methods: The study was carried out in the general medicine outpatient department (OPD) setting for a period of 3 months in our tertiary care teaching and referral hospital. The prescriptions were randomly sampled and the photocopies of all the prescriptions were obtained from the OPD during the period of the study and were processed and analyzed for the demographic profile, drug profile, fixed-dose combinations, therapeutic classes of antibiotic prescribed, morbidity profile according to the disease pattern, and prescription pattern including the errors in prescription and the assessment of polypharmacy.
\end{abstract}

Results: A total of 350 prescriptions were randomly sampled, out of which 312 prescriptions were fit to be analyzed. The total number of drugs in 312 prescriptions was 1022 . Basic information of patient was written in $79.25 \%$ prescriptions, $84.25 \%$ prescriptions were legible, and only $71.21 \%$ prescriptions were complete. The majority of prescriptions had at least five drugs ordered which constituted around $43.14 \%$ of total number of prescriptions leading to polypharmacy.

Conclusions: Our study highlights that there is a scope for improvement in prescribing patterns in areas of writing legible and complete prescriptions. To lay down the principles of rational pharmacotherapeutics, proper training of the prescribers on rational prescription writing is the need of an hour for improving the quality of prescriptions.

Keywords: Prescription auditing, Drug utilization pattern, Rational prescription, Polypharmacy.

(c) 2019 The Authors. Published by Innovare Academic Sciences Pvt Ltd. This is an open access article under the CC BY license (http://creativecommons. org/licenses/by/4. 0/) DOI: http://dx.doi.org/10.22159/ajpcr.2019.v12i12.35401

\section{INTRODUCTION}

The prescription order written by an authorized person is a medicolegal document which is an important link between the doctor and the patient. Various prescribing errors are a direct result of irrational drug prescribing habits, which are now prevailing in a majority of healthcare settings. According to the World Health Organization (WHO), "the rational use of drugs requires that patients receive medications appropriate to their clinical needs, in doses that meet their own individual requirements for an adequate period of time, at the lowest cost to them and their community" [1].

Bad prescribing habits include misuse, overuse, and underuse of medicines, which can lead to unsafe treatment, health hazards, and economic burden on the patients and wastage of resources. Prescribing errors promote the irrational use of drugs and decrease the patient compliance [2]. Such practices also lead to the emergence of drug interactions, drug resistance and adverse drug reactions, which increase mortality, morbidity, and financial burden on the patient [3]. Drugs in the prescriptions are also often written without knowledge about the relevance or potential hazards of polypharmacy [4].

Prescription auditing is a quality improvement process that seeks to improve patient care and outcomes through a systematic review of care against explicit criteria and the implementation of change. This vigilance activity is beneficial in clinical practice in terms of reducing the burden of disease because of medication errors [5].

Prescription auditing involves critical analysis of how the prescription is written as compared to the internationally accepted criteria given by the WHO as a guide for good prescription writing [6]. A set of core prescribing indicators is formulated by the WHO for the rational use of drugs. This set includes the prescribing indicators, the patient care indicators, and the facility indicators. The prescription auditing studies are been conducted in different settings all over the world based on the above prescribing indicators $[7,8]$.

The primary aim of the prescription auditing studies is to improve the quality of health care being provided in various health-care settings. As per our knowledge, no study has been conducted in our outpatient facility, so this study was done to measure the health-care indicators by obtaining the data for rational drug use.

\section{Objectives}

The objectives are as follows:

1. To analyze the prescription profile so as to determine the total number of drugs prescribed and to calculate the average number of drugs ordered per prescription, to measure polypharmacy

2. To analyze the prescriptions for the major classes of drugs prescribed, percentage of generic and fixed-dose combinations, number of drugs taken from the essential drug list (EDL) including the completeness of prescription in all respects and legibility.

\section{METHODS}

Study design and site

The present study is a prospective outpatient department (OPD)based study which was carried out in the medicine department of Era's Lucknow Medical College and Hospital, Lucknow, Uttar Pradesh, India.

\section{Study duration}

The study was conducted over a period of 3 months. 


\section{Study procedure}

Doctors and health-care providers were informed regarding the aims, objectives, and methods of the study with the help of certain information sheets, which are designed mainly for the purpose of the study. Photocopies of all the prescriptions were obtained from the medicine OPD on their specific OPD days during the period of the study. The prescriptions collected from the doctors were analyzed using a spreadsheet with the WHO core drug prescribing indicators, on the basis of the following parameters.

- General details of the prescriber

- Name of the prescriber

- Contact number and address of the prescriber

- Designation.

- General details of the patient

- Name

- Age

- Sex

- Address.

- Date of consultation

- OPD registration number

- Legible handwriting

- Generic name of the drug

- Dosage form of the drug

- Strength of the drug

- Correct dose

- Frequency of administration

- Duration of treatment

- History including chief complains of the patient

- Presumptive/definitive diagnosis

- Investigations

- Number of drug items written on the prescription

- Number of antibiotics prescribed

- Number of injections prescribed

- Total number of drugs prescribed for the EDL

- Legible signature

- Medical council registration number.

The data obtained were processed with the help of Microsoft Excel and were analyzed using SPSS version 25.0 .

\section{RESULTS}

Out of 350 prescriptions collected, only 312 stood appropriate for analysis. All of them had patient name mentioned, but the other basic and necessary details were missing. Age and sex of the patient, OPD registration number and prescribers' details were not documented in some of the prescriptions. The total number of drugs prescribed in 312 prescriptions was 1022 . Therefore, average number of drugs per prescription is 3.27

Demographic profile of the patient was found to be as follows - age distribution of infants $(0-1$ years) was $6.25 \%$, toddlers (2-5 years) was $3.88 \%$, children (6-9 years) was $8.12 \%$, adolescent ( $10-19$ years) was $10.02 \%$, adults (20-60 years) was $59.7 \%$, and elderly (>60 years) was only $5.6 \%$ (Fig. 1). There were $62.32 \%$ males and $33.12 \%$ female patients (Fig. 2). Age was not documented in $6.43 \%$ of prescriptions. Sex was not mentioned in $4.56 \%$ of cases.

Drugs prescribed by generic names constituted only $4.12 \%$ of cases. In $35.27 \%$ of cases, fixed-dose combinations were used. Fixed-dose combinations of amoxicillin with clavulanic acid were ordered in majority of prescriptions, i.e., $4.12 \%$ which was followed by antipyretic, analgesic, and serratiopeptidase combination constituting to $22.65 \%$, followed by multivitamins $18.15 \%$, beta-blockers with calcium channel blockers $6.40 \%$, and mucolytics with bronchodilators 5.97\%, and the combination of norfloxacin with tinidazole was used the least which was in only $5.71 \%$ of cases. In $5.12 \%$ of cases more than one antibiotic was prescribed. Only $84.25 \%$ prescriptions were legible and only $50.81 \%$ prescriptions were complete with respect to dose,

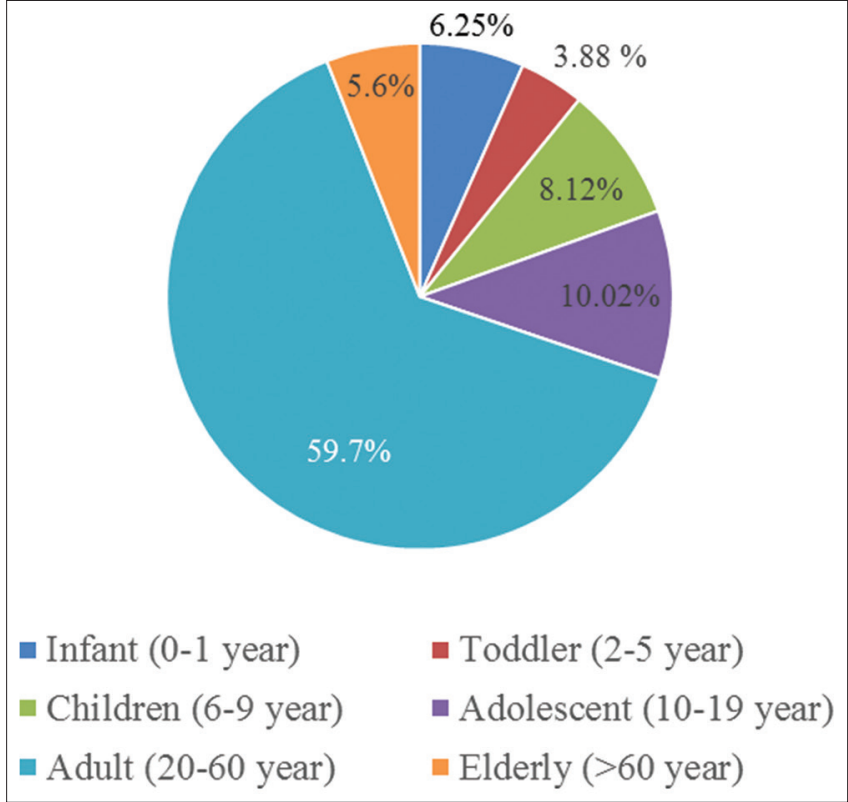

Fig. 1: Age distribution of patients

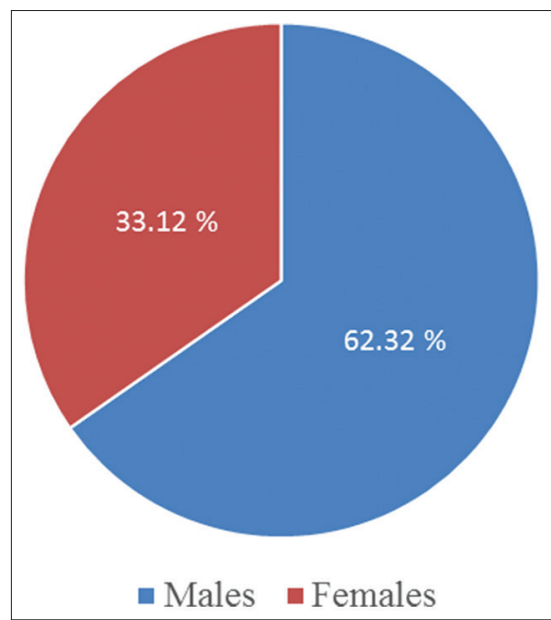

Fig. 2: Sex distribution of patients

dosage forms, frequency, and route of administration mentioned on the prescription (Table 1).

Only $51.75 \%$ of drugs out of the total number of drugs were ordered from the EDL. The majority of medications, i.e., $91.62 \%$ were prescribed in their oral dosage forms followed by injectables which were $5.13 \%$ and also the topical dosage forms which constituted only 3.25\% of total number of drugs. The majority of drugs which were prescribed were antibiotics which were approximately $32.22 \%$. Antibiotics belonging to the cephalosporin class of drugs were prescribed most commonly, accounting to $60.15 \%$. Macrolides prescribed were around $21.22 \%$ of the total antibiotics, followed by penicillin group, quinolones, and the least reported were aminoglycosides constitute only $1.34 \%$ of total antibiotics ordered. This was followed by nonsteroidal anti-inflammatory drugs (NSAIDs), cardiovascular drugs, expectorants and bronchodilators, antiulcer drugs, antihistaminic drugs, and the least which were prescribed which were the mineral and enzymes only $8.11 \%$ of total drugs. Thus, a variable drug prescribing pattern is shown in Table 2.

In all the prescriptions analyzed, the maximum duration of treatment which was advised to the patients was of 3-5 days in around $40.12 \%$ 
Table 1: Prescription profiles

\begin{tabular}{|c|c|c|}
\hline S. No. & Parameters & $\begin{array}{l}\text { No. of } \\
\text { prescriptions (\%) }\end{array}$ \\
\hline 1. & Drugs prescribed by generic names & $12(4.12 \%)$ \\
\hline 2. & Fixed-dose combinations & $110(35.27)$ \\
\hline a. & $\begin{array}{l}\text { Combination of antipyretic, } \\
\text { analgesic and serratiopeptidase }\end{array}$ & $25(22.65)$ \\
\hline b. & $\begin{array}{l}\text { Combination of mucolytics and } \\
\text { bronchodilators }\end{array}$ & $7(5.97)$ \\
\hline c. & $\begin{array}{l}\text { Combination of beta blockers and } \\
\text { calcium channel blockers }\end{array}$ & $7(6.40)$ \\
\hline d. & $\begin{array}{l}\text { Combination of amoxicillin and } \\
\text { clavulanic acid }\end{array}$ & $45(41.12)$ \\
\hline e. & $\begin{array}{l}\text { Combination of norfloxacin and } \\
\text { tinidazole }\end{array}$ & $6(5.71)$ \\
\hline f. & Multivitamins & $20(18.15)$ \\
\hline 3. & $\begin{array}{l}\text { Antibiotics prescribed }>1 \text { per } \\
\text { prescription }\end{array}$ & $15(5.12)$ \\
\hline 4. & Legible prescriptions & $263(84.25)$ \\
\hline 5. & Complete prescriptions & $159(50.81)$ \\
\hline
\end{tabular}

Table 2: Drug profiles

\begin{tabular}{lll}
\hline S. No. & Parameters & $\begin{array}{l}\text { Number of } \\
\text { drugs (\%) }\end{array}$ \\
\hline 1. & Drugs on EDL & $528(51.75)$ \\
2. & Dosage forms & $937(91.62)$ \\
a. & Oral drugs & $52(5.13)$ \\
b. & Injectables & $33(3.25)$ \\
c. & Topical drugs & $329(32.22)$ \\
3. & Antibiotics prescribed & $198(60.15)$ \\
a. & Cephalosporins & $70(21.22)$ \\
b. & Macrolides & $40(12.12)$ \\
c. & Penicillin & $17(5.17)$ \\
d. & Quinolones & $4(1.34)$ \\
e. & Aminoglycosides & $205(20.12)$ \\
4. & NSAIDs & $94(9.18)$ \\
5. & Anti-ulcer drugs & $86(8.42)$ \\
6. & Antihistaminic drugs & $108(10.53)$ \\
7. & Expectorants and bronchodilators & $117(11.42)$ \\
8. & Cardiovascular drugs & $83(8.11)$ \\
9. & Minerals, enzymes, and miscellaneous & \\
\hline
\end{tabular}

EDL: Essential drug list, NSAIDs: Nonsteroidal anti-inflammatory drugs

of cases, followed by 6-7 days in $27.01 \%$ cases, $8-10$ in $11.08 \%$ cases, and even more than 10 days in $10.5 \%$ of cases. In only $9.17 \%$ of cases the treatment was of a shorter duration of 1-2 days, and a single dose of treatment was only reported in a mere $2.12 \%$ of cases (Table 3 ).

Majority of presumptive or definitive diagnosis which was encountered was related to the digestive system which was in around $45.77 \%$ of cases, followed by the diseases of respiratory system were $20.19 \%$, cardiovascular system $12.52 \%$, and infectious and parasitic infestations $10.04 \%$. The least common diagnosis mentioned was pertaining to the diseases of musculoskeletal system, central nervous system, and skin. About 2.12\% of burn and trauma cases were also reported (Table 4).

Certain common errors were reported in the majority of prescriptions analyzed, which were related to incomplete prescriptions like in some cases the basic and foremost details of the patients such as their age and sex were not written, others even lack probable or definitive diagnosis. There were some prescriptions wherein date, OPD registration number, even the details, and legible signature of the doctor were not mentioned (Table 5).

In many prescriptions, there was excessive number of drugs prescribed, which was inappropriate and led to polypharmacy. The maximum number of drugs prescribed reported was seven and more in 10 (3.08\%) cases, and majority of the prescriptions analyzed did have at least five
Table 3: Treatment duration profile

\begin{tabular}{lll}
\hline S. No. & Duration & Number of prescriptions (\%) \\
\hline 1. & Single dose & $6(2.12)$ \\
2. & $1-2$ days & $28(9.17)$ \\
3. & $3-5$ days & $125(40.12)$ \\
4. & $6-7$ days & $84(27.01)$ \\
5. & $8-10$ days & $34(11.08)$ \\
6. & $>10$ days & $33(10.5)$ \\
\hline
\end{tabular}

Table 4: Morbidity profile

\begin{tabular}{lll}
\hline S. No. & Disease pattern & $\begin{array}{l}\text { No. of } \\
\text { prescriptions (\%) }\end{array}$ \\
\hline 1. & Diseases of digestive system & $142(45.77)$ \\
2. & Diseases of respiratory system & $62(20.19)$ \\
3. & Infections and parasitic infestations & $31(10.04)$ \\
4. & Diseases of skin & $4(1.51)$ \\
5. & Diseases musculoskeletal system & $10(3.12)$ \\
6. & Diseases of cardiovascular system & $39(12.52)$ \\
7. & Diseases of the central nervous system & $14(4.73)$ \\
8. & Burn and trauma cases & $6(2.12)$ \\
\hline
\end{tabular}

Table 5: Common errors in prescriptions

\begin{tabular}{|c|c|c|}
\hline S. No. & Error & No. of prescriptions (\%) \\
\hline 1. & Age of the patient not written & 25 (8.12) \\
\hline 2. & Sex of the patient not written & $18(5.85)$ \\
\hline 3. & Date not written & $6(2.12)$ \\
\hline 4. & Diagnosis not written & $34(11.12)$ \\
\hline 5. & $\begin{array}{l}\text { Name and address of the } \\
\text { doctor not mentioned }\end{array}$ & $16(5.23)$ \\
\hline 6. & $\begin{array}{l}\text { OPD registration no. not } \\
\text { mentioned }\end{array}$ & $16(5.18)$ \\
\hline 7. & $\begin{array}{l}\text { Duration of treatment not } \\
\text { mentioned }\end{array}$ & $14(4.45)$ \\
\hline 8. & $\begin{array}{l}\text { Legible signature of the } \\
\text { doctor is absent }\end{array}$ & $22(7.12)$ \\
\hline \multicolumn{2}{|c|}{ Total prescriptions with errors } & $151(49.19)$ \\
\hline
\end{tabular}

OPD: Outpatient department

drugs ordered in them, which constituted to around 135 (43.14\%) of total prescriptions (Fig. 3).

\section{DISCUSSION}

Prescription writing is a mode of the therapeutic intervention for the patient by the doctor and this skill is acquired through training. It is the legal duty of the practitioner to write legible and complete prescriptions, as the quality of prescriptions directly reflects the competence of physician and his efficiency of rational prescribing.

However, systematic reviews suggest that prescribing errors are common and can affect from 4.2 to $82 \%$ of prescriptions [9]. These prescribing errors can also cause adverse effects. Almost four in 1000 prescriptions have errors having the potential to cause adverse reactions [10]. Individual and system-related factors are responsible for prescribing errors [11]. Systematic analysis of prescriptions can identify these errors by prescription auditing [12]. Prescription auditing is the mainstay of quality assurance in hospitals, as the audit data which are collected are of much importance to the hospital administration, healthcare professionals and drug manufacturers as the data are worthy in making better decision and drafting specific policies.

In our study, the total number of drugs analyzed in 312 prescriptions was 1022. Therefore, average number of drugs per prescription is 3.27. This number is quite higher than the recommended limit for the 


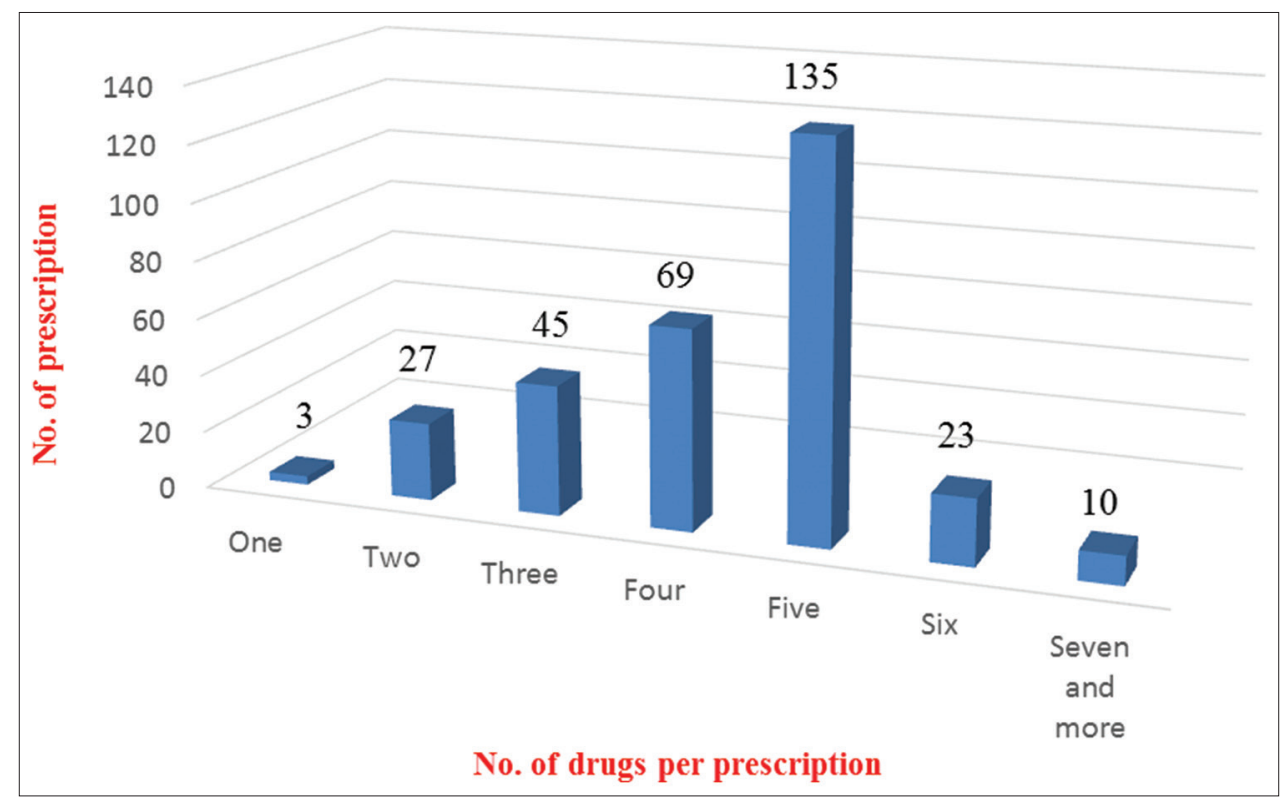

Fig. 3: Polypharmacy

average number of drugs to be prescribed per prescription that is 2.0. The almost same finding was noticed in a study done by Senthilselvi et al. where an average number of drugs per prescription was 4.29 which is greater than double the average number (i.e., 2) recommended by the WHO [13]. The risk of drug interactions is directly proportional to the increase in average number of drugs per prescription. Rational pharmacotherapeutics can play a great role in this regard if introduced.

Some brand names (proprietary names) and generic names (nonproprietary names) sound or appear to be similar to certain other drugs when spoken or written. These are known as look-alike-soundalike medications. With thousands of similar drugs currently present in the market, this confusion can be a leading cause of medication error, which could be harmful or even can be proved fatal to the patient. This is only because these drugs have names which appear similar, when are carelessly written, liable to misinterpretation. There are certain examples of confused drug name pairs such as losec (omeprazole) and lasix (furosemide), Celebrex (celecoxib) and Cerebyx (fosphenytoin), almarl (arotinolol) and Amaryl (glimepiride), and Lantus (insulin glargine) and Lanvis (thioguanine), which are problematic worldwide. Proper prescription auditing can avoid or decrease this confusion or misinterpretation caused by illegible prescribing.

Based on the findings in our study, certain prescription practices need improvement as soon as possible. As to quote an example in some of the prescriptions, age, sex, address, and OPD registration number were missing. In others, prescribers' initials were not found. These errors make the prescription invalid, as certain drugs can only be dispensed with a valid prescription of the doctor. The prescription errors analyzed by our study were in correlation with errors found in another study done by Ahsan et al. where $17 \%$ of prescriptions lack the initials of the prescriber [9], leading to serious dosing and dispensing errors. In a study done by Seden et al., it has been suggested that electronic prescribing can eliminate these errors through cautions and alerts at the time of prescribing drugs [14].

In this study, the drugs prescribed by generic names are only in $4.12 \%$ of cases, which are quite less. As if drugs are prescribed with their generic names, there are reduced chances of dispensing errors, decreased economic burden on the patients, and less undue wastage of resources. Drugs on EDL are only $51.75 \%$ of drugs are on EDL, which is comparable to another study done by Hazra et al., in India [15].

Dosage forms which were used constituted to around $91.62 \%$ oral, $5.13 \%$ injectables, and $3.25 \%$ topical forms. Injections were prescribed in $5.13 \%$ of encounters, which is in accordance with the accepted range as proposed by the WHO $(\leq 10 \%)$, similar to a study done by Abidi et al. in a hospital of Western UP, India [5]. Prescribing injectable in cases where oral dosage forms are more beneficial and appropriate, is an irrational deed as the cost of the injections is much higher as compared to the oral forms. Inappropriate and unnecessary use of injectables also increases the risk of HIV and other blood-borne injections [16].

The antibiotics prescribed were around $32.22 \%$, which is higher than the designated range by the WHO $(\leq 30 \%)$. The percentage of encounters was around $39 \%$, which was comparable to a study done by Ahsan et al. [9]. More than one antibiotic is prescribed in 5.12\%\% of cases. This finding was similar to a study done by Gupta et al., where majority of patients received more than one antibiotic [17]. Overuse of antibiotics due to their over prescription is leading to a greater increase in antibiotic resistance. About $29.63 \%$ of prescriptions had fixed-dose combinations, which is quite greater when compared to another study done in India by Chakrabarti [18]

Complete prescriptions reported related to dosage form, dose, frequency, route of administration, patient's and prescriber's details and other necessary information were only $50.81 \%$, and only $84.25 \%$ of prescriptions were legible. One hundred fifty-one prescriptions (49.19\%) out of 312 analyzed had common errors of prescribing.

Polypharmacy which is the unnecessary administration of an excessive number of drugs and medicines at the same time is regarded as the chief form of malpractice among prescribers, and it was also documented to some extent in this study. A majority of prescriptions (43.14\%) analyzed had an order of five drugs prescribed which is quite larger as compared to a study done by Balaji et al. where the percentage of prescriptions containing more than five drugs was 3.8\%, a significantly lower percentage than our study [19]. Study done by Siddarama et al. has also shown results with prescriptions that contain more than 6 drugs in $91.57 \%$ of prescriptions [20].

There were also certain prescriptions, though less in number (3.08\%) in which seven and more drugs were ordered. The average consultation time with the doctor is $3.2 \mathrm{~min}$, which is the time taken by the patient from entering the doctor's room for consultation to leaving it which is a very short period assigned for the total process of consultation, which mainly involves taking a proper history including the chief complaints, clinical evaluation, and prescribing appropriate drugs. The time for dispensing the drug is $1.8 \mathrm{~min}$, which is also insufficient as more 
dispensing time should be given to the pharmacist so that they could deliver the right drug.

Most common categories of drug prescribed to the patient were antibiotics $32.22 \%$, NSAIDs $20.12 \%$, cardiovascular drugs $11.42 \%$, anti-ulcer drugs $9.18 \%$, antihistaminic $8.42 \%$, expectorants and bronchodilators $10.53 \%$, and minerals and enzymes $8.11 \%$.

The handwriting of doctors is also ill-legible in the majority of prescriptions, which causes confusion leading to loss of information in terms of follow-up advice, do's and don'ts, reasons for referrals, dose, and dosing schedule of the drug which should be followed appropriately. There is still a huge scope of improvement in writing prescriptions rationally, after detecting such large number of loopholes within the study.

\section{CONCLUSIONS}

Prescription auditing can reflect major errors pertaining to dosing, completeness of the prescription, clearly documented instructions, absence of signature of the authorities, and poor legibility. The prescribing errors further in future lead to adverse effects and unnecessary wastage of resources. This is also a direct indicator of polypharmacy. The foremost duty of the physician is to educate the masses not to take inappropriate and unnecessary medication and for this there should be a proper educational curriculum or workshop mainly which should emphasize general practitioners to prescribe drugs with generic names and from the EDL. Regular training of healthcare professionals in this respect will lead to awareness and motivation among prescribers toward rational prescribing. Electronic prescribing techniques and regular prescription review at all times guarantee safe treatment and rational drug use.

\section{AUTHORS' CONTRIBUTIONS}

All the authors contributed equally to the paper.

\section{CONFLICTS OF INTEREST}

The authors declare that they have no conflicts of interest.

\section{REFERENCES}

1. Sisay M, Mengistu G, Molla B, Amare F, Gabriel T. Evaluation of rational drug use based on World Health Organization core drug use indicators in selected public hospitals of Eastern Ethiopia: A cross sectional study. BMC Health Serv Res 2017;17:161.

2. Fijn R, Van den Bemt PM, Chow M, De Blaey CJ, De Jong-Van den Berg LT, Brouwers JR. Hospital prescribing errors: Epidemiological assessment of predictors. Br J Clin Pharmacol 2002;53:326-31.

3. Singh R. Prescription audit and assessment of drug use pattern using World Health Organization prescribing indicators in a tertiary care teaching and referral hospital in Himachal Pradesh, India. J Med Sci Clin Res 2018;6:377-84.

4. Himmel W, Lönker B, Kochen MM. Nonformulary drug requests at an academic hospital in Germany-the role of general practitioners' longterm medication. Eur J Clin Pharmacol 1998;54:41-6.

5. Abidi A, Gupta S, Kansal S, Ramgopal R. Prescription auditing and drug utilization pattern in a tertiary care teaching hospital of Western UP. Int J Basic Clin Pharmacol 2012;1:184.

6. Dyasanoor $\mathrm{S}$. Insight into quality of prescription writing-an instituitional study. J Clin Diagn Res 2016;4:564-70.

7. Devi DP, George J. Diabetic nephropathy: Prescription trends in tertiary care. Indian J Pharm Sci 2008;70:374.

8. Prinja S, Tripathy J, Bahuguna P. Drug prescription behavior: A crosssectional study in public health facilities in two states of North India. Perspect Clin Res 2018;9:76.

9. Ahsan M, Shaifali I, Mallick AK, Singh HK, Verma S, Shekhar A. Prescription auditing based on World Health Organization (WHO) prescribing indicators in a teaching hospital in North India. Int J Res Med Sci 2016;4:1847-52.

10. Velo GP, Minuz P. Medication errors: Prescribing faults and prescription errors. Br J Clin Pharmacol 2009;67:624-8.

11. Reason J. Human error: Models and management. BMJ 2000;320:768-70.

12. Montesi G, Lechi A. Prevention of medication errors: Detection and audit. Br J Clin Pharmacol 2009;67:651-5.

13. Senthilselvi R, Boopana M, Sathyan L, Visuvasam P, Ganesan V. Drug utilization pattern in paediatric patient in a secondary care hospital. Int $\mathrm{J}$ Pharm Pharm Sci 2019;22:69-74

14. Seden K, Kirkham JJ, Kennedy T, Lloyd M, James S, Mcmanus A, et al. Cross sectional study of prescribing errors in patients admitted to nine hospitals across North West England. BMJ 2013;3:321-30.

15. Hazra A, Tripathi SK, Alam MS. Prescribing and dispensing activities at the health facilities of a non-governmental organization. Natl Med J India 2000;13:177-82

16. Hutin YJ. Use of injections in healthcare settings worldwide, 2000: Literature review and regional estimates. BMJ 2003;327:1075.

17. Gupta N, Gupta, D, Sharma, Garg SK, Bhargava VK. Auditing of prescriptions to study utilization of antimicrobials in a tertiary hospital. Indian J Pharmacol 1997;29:411-5.

18. Chakrabarti A. Prescription of fixed dose combination drugs for diarrhoea. Indian J Med Ethics 2007;4:174-83.

19. Balaji R, Sekkizhar M, Kumar MA, Nirmala P. An observational study of drug utilization pattern and pharmacovigilance of antipsychotics. Int J Curr Pharm Res 2017;9:56.

20. Siddarama R, Naidu JB, Joshisree KP, Lakshmi VS. Polypharmacy induced drug interactions, adverse drug reactions (ADR) and medication errors in tertiary care South Indian hospital. Int J Pharm Pharm Sci 2019;5:88-93 